\title{
Clinical and MRI features about two types of silent cerebral small-vessel disease in type-2 diabetes mellitus: a retrospective cross-sectional study in a tertiary hospital
}

\author{
Dan-Qiong Wang ${ }^{1,2}$, Lei Wang ${ }^{2}$, Xiao-Shuang Xia ${ }^{1}$, Miao-Miao Wei ${ }^{1}$, Xiao-Lin Tian ${ }^{1}$, Liang-Fang Wang ${ }^{3}$, \\ Xin $\mathrm{Li}^{1}$ \\ ${ }^{1}$ Department of Neurology, the Second Hospital of Tianjin Medical University, Tianjin, China; ${ }^{2}$ Department of General Medical, Shanxi Bethune \\ Hospital, Shanxi Academy of Medical Sciences, Tongii Shanxi Hospital, Third Hospital of Shanxi Medical University, Taiyuan, China; ${ }^{3}$ Department \\ of Thoracic Surgery, Shanxi Bethune Hospital, Shanxi Academy of Medical Sciences, Tongji Shanxi Hospital, Third Hospital of Shanxi Medical \\ University, Taiyuan, China
}

Contributions: (I) Conception and design: DQ Wang, XS Xia, X Li; (II) Administrative support: L Wang; (III) Provision of study materials or patients: LF Wang; (IV) Collection and assembly of data: MM Wei; (V) Data analysis and interpretation: XL Tian; (VI) Manuscript writing: All authors; (VII) Final approval of manuscript: All authors.

Correspondence to: Xin Li. Department of Neurology, the Second Hospital of Tianjin Medical University, No. 23 Pingjiang Road, Hexi District, Tianjin 300211, China. Email: lixin_dhuf@163.com.

Background: The present study aimed to evaluate the frequency of silent cerebral small-vessel disease, especially lacunes and white matter hyperintensities, in patients with or without the impaired glucose tolerance (IGT) and type-2 diabetes mellitus, and to characterize the diabetes-correlated factors related to silent cerebral small-vessel disease.

Methods: This is a retrospective cross-sectional study. Totally 698 patients were included in this study, from January 2014 to December 2019, among which 270 patients were included in the diabetes mellitus group, 106 patients were included in the IGT group, and 322 patients were included in the Control group. All patients underwent magnetic resonance imaging to investigate the silent cerebral small-vessel disease: the lacunes and the white matter hyperintensities. All the baseline information and diabetes-related factors, such as glycated hemoglobin level, insulin usage, etc., were collected. Then correlation analysis and regression analysis were used to explore the correlation between diabetes with related risk factors and silent cerebral small-vessel disease.

Results: Lacunes and white matter hyperintensities were more common in the diabetes mellitus group than in the IGT group and the Control group, with an occurrence of lacunes of $83.3 \%$ vs. $70.8 \%$ vs. $70.4 \%$ $(\mathrm{P}=0.003)$, respectively, and an occurrence of white matter hyperintensities of $41.1 \%$ vs. $24.5 \%$ vs. $31.1 \%$ $(\mathrm{P}=0.003)$, respectively. The occurrence of lacunes was correlated with the duration of diabetes mellitus [odds ratio $(\mathrm{OR})=1.483,95 \%$ confidence interval $(\mathrm{CI}): 1.082-2.031, \mathrm{P}=0.009]$ and the age $(\mathrm{OR}=1.141,95 \% \mathrm{CI}$ : $1.102-1.180, \mathrm{P}<0.001)$, while white matter hyperintensities were independently correlated only with the age (OR $=1.124$, 95\% CI: 1.094-1.155, $\mathrm{P}<0.001)$.

Conclusions: Lacunes and white matter hyperintensities, are more common in the diabetes mellitus patients than in the IGT patients or in the other patients. The occurrence of lacunes was correlated with the duration of diabetes mellitus and the age, while the occurrence of white matter hyperintensities was independently correlated with the age.

Keywords: Cerebral small-vessel disease (CSVD); type-2 diabetes mellitus; magnetic resonance imaging (MRI); lacunes; white matter hyperintensities (WHMs) 
Submitted Aug 06, 2021. Accepted for publication Dec 20, 2021; Published online: 24 Jan 2022.

doi: 10.21037/qims-21-786

View this article at: https://dx.doi.org/10.21037/qims-21-786

\section{Introduction}

In China, the prevalence of type-2 diabetes mellitus (DM) is increasing annually, making China one of the countries with the fastest growing incidence of diabetes mellitus worldwide (1). In a recent study, the prevalence of DM was reported to be $10.9 \%$, of which over $60 \%$ of those affected were unaware of their diagnosis. In addition, another $35.7 \%$ of the population was found to have abnormal glucose homeostasis $(2,3)$. The marked increase in the prevalence of DM is mostly attributed to type-2 DM (4), which has resulted in an increased focus on metabolic disorders and vascular diseases caused by this disease.

Cerebral small-vessel disease (CSVD) is an age-related disease that affects the small vessels of the brain (5), and its imaging features are characterized by lacunar infarction (LI), white matter hyperintensities (WMHs), perivascular space enlargement, microbleeds, and brain atrophy (6). One study has confirmed that mild neuropsychological disturbances are not infrequent in acute lacunar infarcts (7). Brain structural abnormalities are considered to be an important pathway for brain diseases caused by type-2 DM. While previous studies have confirmed that type-2 DM is related to an increased risk of structural brain abnormalities such as LIs $(8,9)$ and brain atrophy (9-12), findings on the relationship between type-2 DM and the markers of small-vessel diseases such as WMH (13-17) and cerebral microbleeds (18-22) have not been consistent. Some findings suggest that no difference in periventricular WMHs between patients with and without diabetes mellitus. In contrast, deep WMHs have been found only in the control group (23). No correlations between pre-DM and lacunes, cerebral microbleed (CMBs), WMHs, or smaller brain volumes have been observed in the older population (24).

The objective of the present study was to compare the frequency of CSVD in patients with impaired glucose tolerance (IGT) and type-2 DM and factors related to two types of CSVD, Lacunes and White Matter Hyperintensities. In addition, it aimed to evaluate the relationship between type-2 DM and CSVD at different courses and characterize the DM related variables related to CSVD in patients with type-2 DM.

We present the following article in accordance with the
STROBE reporting checklist (available at https://qims. amegroups.com/article/view/10.21037/qims-21-786/rc).

\section{Methods}

\section{Participants}

This is a retrospective cross-sectional study. From January 2014 to December 2019, patients who met the inclusion and exclusion standards as follows are retrospectively included in this study. Inclusion criteria: (I) patients were between 55 and 85 years old; (II) patients were hospitalized at the General Department of Bethune Hospital in Shanxi Province; (III) according to the diagnostic criteria for diabetes mellitus revised by the World Health Organization (WHO) in 1998 (25), the diagnosis of patients, with or without type-2 DM or IGT, was definitive: oral glucose tolerance test was completed, the results of fasting blood glucose and glycosylated hemoglobin were obtained in three month; (IV) patients underwent brain magnetic resonance imaging (MRI) scans. Exclusion criteria: (I) patients who had been admitted to the hospital as a result of an acute cerebrovascular accident; (II) patients who had had acute complications associated with type-2 DM within 3 months, such as ketoacidosis, severe hypoglycemia lead to loss conscious, and a hyperglycemic hypertonic state; (III) patients with a previous diagnosis of dementia, craniocerebral trauma, or macrovascular complications such as cardiac arrest, heart failure, numbness due to low blood supply to legs; (IV) patients who had recently been administered psychoactive drugs or hormones; (V) patients with incomplete clinical data needed in this study.

A total of 894 people met the inclusion criteria, including 351 people in the DM group, 138 people in the IGT group, and 405 people in the Control group. Total 125 patients refused to participate in the study, and 71 patients with incomplete data were excluded. After all, a total of 698 patients were included in this study, among which 270 patients were in the diabetes mellitus (DM) group, 106 patients were in the IGT group, 322 patients were in the Control group (see Figure 1).

The study was conducted in accordance with the Declaration of Helsinki (as revised in 2013). The study 


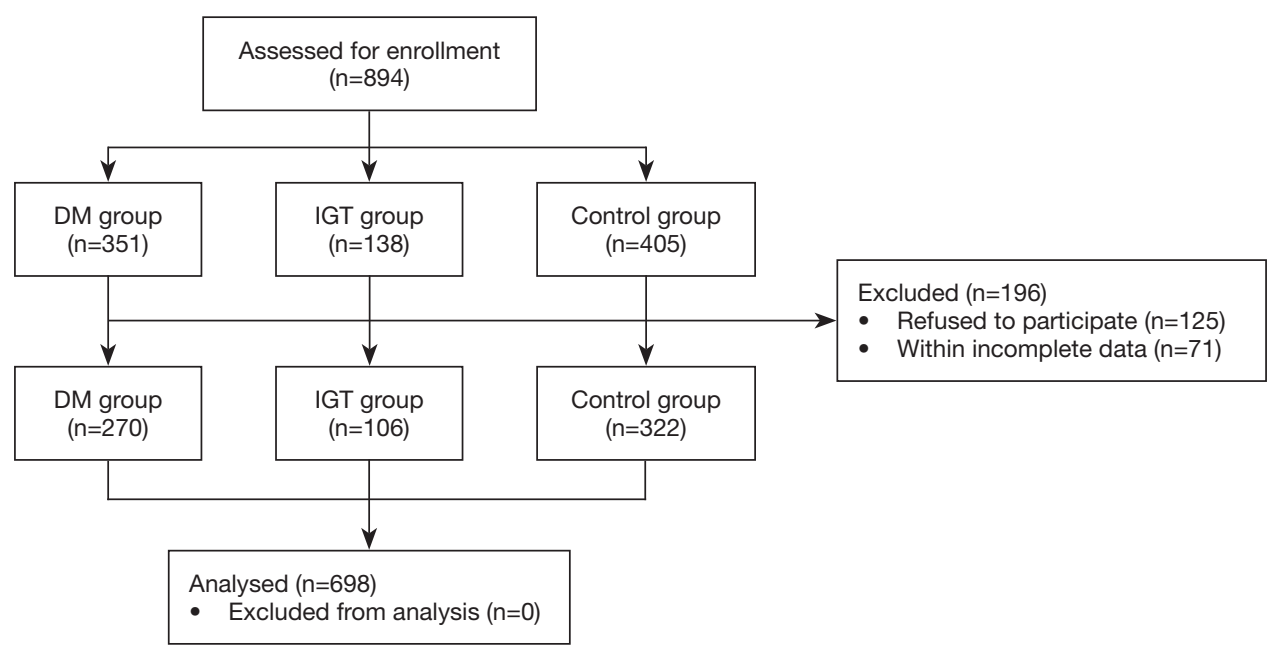

Figure 1 The flow chart of enrollment. DM, diabetes mellitus; IGT, impaired glucose tolerance.

was approved by Ethics Committee of the Shanxi Bethune Hospital (SBQLL-2021-066) and informed consent was taken from all the patients.

\section{Clinical data}

Basic information of patients such as age, gender, and body mass index (BMI) are recorded; the latest results of serum triglycerides (TG), cholesterol (TC), and creatinine (SCr) are recorded; diabetes-related factors such as diabetes course, fasting blood glucose level, HbA1C level, and insulin usage are recorded; cardiovascular and cerebrovascular risks factors such as smoking history, blood pressure status and blood pressure control methods, history of coronary heart disease (CHD), etc. are extracted from the medical system. Hypertension is classified by systolic blood pressure (SBP) according to the accepted standard (26). SBP below $140 \mathrm{mmHg}$ is regarded as normal blood pressure. The three intervals of SBP about $140-160 \mathrm{mmHg}$, $160-180 \mathrm{mmHg}$, and above $180 \mathrm{mmHg}$ are defined as grade 1,2 , and 3 hypertension respectively. All participants take the brain magnetic resonance imaging (MRI) scanning.

\section{MRI scanning protocol}

A unique Siemens Skyra 3.0T superconducting MRI machine was used for scanning, consisting of an axial T1weighted sequence [repetition time (TR)/echo time (TE): 1,800/9 ms], an axial T2-weighted sequence (TR/TE: $3,710 / 99 \mathrm{~ms}$ ), an axial fluid-attenuated inversion recovery sequence (TR/TE/TI: 8,000/81/2,372 ms), and a diffusionweighted imaging sequence (B: $0 / 1,000 \mathrm{~s} / \mathrm{mm}^{2}$ ).

\section{Image processing and evaluation}

Images were evaluated by two experienced radiologists, and every MRI image of participants was assessed three times by each radiologist to ensure the CSVD markers: lacunes and WMHs. The Fazekas scale, which score $\geq 1$ was considered as significant (27), was used to determine the WMH. The neuroradiologists involved had no knowledge of the clinical data or whether the participants had diabetes mellitus.

\section{Statistical analysis}

All results are analyzed by using IBM's SPSS software (version 22.0; IBM, Armonk, NY, USA). The statistical significance is considered to be $\mathrm{P}<0.05$.

Firstly, the general characteristics of the patients in three groups are compared. The parametric variables are presented as means \pm standard deviation (SD) and are compared between the three groups by Analysis of Variance (ANOVA). The nonparametric variables are analyzed using a Mann-Whitney $U$ test, showing as medians (interquartile range). The categorical variables are analyzed using the $\chi^{2}$ test or Fisher's exact test, as appropriate.

Secondly, the patients in the DM group and in the IGT group are seen as a combined population, trying to find the potential risk factors related to the occurrence of lacunes and WMHs. The clinical data of the population with or 
Table 1 General characteristics of the patients

\begin{tabular}{|c|c|c|c|c|}
\hline Category & Control group ( $\mathrm{n}=322$ ) & IGT group ( $\mathrm{n}=106)$ & DM group $(n=270)$ & $P$ \\
\hline Age (years) & 72 [62-79] & $67[58-77]$ & $70[58-78]$ & 0.113 \\
\hline BMI $\left(\mathrm{kg} / \mathrm{m}^{2}\right)$ & $24.191 \pm 3.028$ & $25.314 \pm 2.967$ & $25.839 \pm 3.495$ & $<0.001^{* a, b}$ \\
\hline TC (mmol/L) & $4.350 \pm 1.067$ & $4.325 \pm 1.029$ & $4.380 \pm 1.122$ & 0.893 \\
\hline Hypertension history & $201(62.4)$ & 78 (73.6) & $201(74.4)$ & $0.004^{* \mathrm{~b}}$ \\
\hline BP satisfied controlled & $166(51.6)$ & $54(50.9)$ & $113(41.9)$ & $0.048^{\star}$ \\
\hline $\mathrm{BP}$ & & & & $0.005^{\star \mathrm{b}}$ \\
\hline Normal & $121(37.6)$ & $28(26.4)$ & $69(25.6)$ & \\
\hline Grade 3 (>180 mmHg) & $126(39.1)$ & $41(38.7)$ & 107 (39.6) & \\
\hline CHD history & $51(15.8)$ & $13(12.3)$ & $50(18.5)$ & 0.319 \\
\hline Using antihypertensive drugs & $169(52.5)$ & $64(60.4)$ & $176(65.2)$ & $0.012^{\star \mathrm{b}}$ \\
\hline Using statins & $96(29.8)$ & $31(29.2)$ & $105(38.9)$ & $0.042^{*}$ \\
\hline Using aspirin & $86(26.7)$ & $29(27.4)$ & $108(40.0)$ & $0.001^{\star b}$ \\
\hline Smoking & $118(36.6)$ & $44(41.5)$ & $126(46.7)$ & $0.048^{\star b}$ \\
\hline $\mathrm{FBG}(\mathrm{mmol} / \mathrm{L})$ & $5.070 \pm 0.483$ & $6.160 \pm 1.185$ & $7.716 \pm 2.583$ & $<0.001^{\star a, b, c}$ \\
\hline $\mathrm{HbA}_{1} \mathrm{C}$ management & & & & $<0.001^{* \mathrm{~b}, \mathrm{c}}$ \\
\hline
\end{tabular}

Data are expressed as $\mathrm{n}(\%)$, median (interquartile range), or mean $\pm \mathrm{SD}$. ${ }^{*}, \mathrm{P}<0.05$, the difference is statistically significant. a, the difference between IGT group and Control group has statistically significant; $b$, the difference between DM group and Control group has statistically significant; c, the difference between DM group and IGT group has statistically significant. IGT, impaired glucose tolerance; DM, diabetes mellitus; BMI, body mass index; TC, total cholesterol; TG, triglyceride; SCr, serum creatinine; WMH, white matter hyperintensities; FBG, fasting blood glucose; CHD, coronary heart disease; HBP, high blood pressure; BP, blood pressure.

without lacunes and WMHs are analyzed by independent samples $t$-test, Mann-Whitney U test, $\chi^{2}$ test or Fisher's exact test, as appropriate.

Thirdly, the variables showed significant differences in two steps before, especially the diabetic-related factors, are included in the Logistic regression analysis to determine independent associations between the type-2 DM and the lacunes and the WMHs (stepwise regression method, entry: $\mathrm{P}=0.05$; removal $\mathrm{P}=0.10$ ). The results are presented as an odds ratio (OR), a $95 \%$ confidence interval $(95 \% \mathrm{CI})$ and a $\mathrm{P}$ value.

\section{Results}

\section{The general characteristics of the participants}

The clinical characteristics of the three groups are shown in Table 1. There were no significant differences in age and gender $(\mathrm{P}>0.05)$, but the BMI distribution was different. As expected, fasting blood glucose and HbA1C levels were higher in the IGT group and the DM group. There were no significant differences in fasting cholesterol and creatinine levels between the groups. The total frequency of hypertension was higher in the IGT group and the DM 
group. After the classification of hypertension, it was found that grade 1 and 2 hypertension in the partial patients was higher than in the control group, and the control rate worsened as patients with impaired glucose tolerance and type-2 diabetes mellitus used less antihypertensive drugs, with a statistically significant difference $(\mathrm{P}<0.05)$. The type-2 DM group took more aspirin and statins than the other groups, and there were more patients with a history of smoking in the IGT and DM groups, but there was no statistically significant difference in the number of years of smoking when compared with the Control group $(\mathrm{P}>0.05)$. In terms of MRI manifestations, more patients with lacunes and WMHs were found in the DM group (83.3\% and $41.1 \%$, respectively), with a statistically significant difference in comparison with the Control group $(\mathrm{P}<0.05)$.

\section{Potential risk factors related to Lacunar infarction in the DM group and IGT group}

A comparison of the clinical characteristics in patients in IGT groups and DM groups with or without lacunes is shown in Table 2. There were significant differences between the two groups in relation to diabetes mellitus duration, $\mathrm{HbA1C}$, and the use of insulin. The incidence of lacunes increased remarkably after $\geq 5$ years of diabetes mellitus, but there were no significant differences in the history, grading, and management of high blood pressure $(\mathrm{P}>0.05)$ between the two groups. However, it was observed that there was a higher incidence of hypertension in the patients with lacunes, and there were more patients with grade 2 and 3 hypertension than in the control group. The medication ratio in the patients with lacunes in these two groups was higher, but the proportion of patients with poor blood pressure control in the two groups was higher than that of the control group. There were with difference in the history of CHD, the use of statins, and the use of aspirin between the two groups.

\section{Potential risk factors related to WMHs in the DM group and IGT group}

The comparison of the clinical characteristics of the patients with impaired glucose tolerance and type-2 diabetes mellitus with or without WMHs is shown in Table 3. There were significant differences in the diabetes mellitus duration and the use of insulin between the two groups; the incidence of WMHs increased remarkably after $\geq 10$ years of diabetes mellitus. There was no difference in the HbA1C control between the two groups. In addition, there were no significant differences in the history of hypertension, hypertension management, and the use of antihypertensive drugs $(P>0.05)$ between the two groups, but the incidence of grade 2 hypertension was higher among the patients with WMHs following the classification of hypertension $(\mathrm{P}<0.05)$. There were differences in the history of CHD, statins, use of aspirin, history of smoking, and years of smoking between the two groups.

\section{The relationship between the diabetes-related factors and brain changes (lacunes, WMHs) in patients in the DM group}

Table 4 set out the results of the regression analysis. The occurrence of lacunes was correlated with the duration of diabetes mellitus [odds ratio $(\mathrm{OR})=1.483,95 \%$ confidence interval (95\% CI): $1.082-2.031, \mathrm{P}=0.009]$ and the age (OR $=1.141,95 \%$ CI: $1.102-1.180, \mathrm{P}<0.001)$, while WMHs were independently correlated only with the age (OR $=1.124,95 \%$ CI: $1.094-1.155, \mathrm{P}<0.001)$. So, the duration of diabetes and the age of patients are risk factors for the silent CSVD.

The management of HbA1C levels, history of CHD, smoking history and years of smoking, aspirin use, and the use of statins were not correlated with brain changes in diabetic patients. In addition, no differences in brain changes were found between the type- 2 diabetics using oral hypoglycemic drugs and those using insulin.

\section{Discussion}

Current studies demonstrate that compared with the control, type-2 diabetes mellitus is correlated with the classic MRI markers of CSVD (lacunes and WMHs). Diabetes mellitus duration is correlated with the occurrence of lacunes rather than WMHs, while the occurrence of WMHs is independently correlated with age. However, HbA1C management and use of insulin are not correlated with either type of CSVD.

Previous studies have demonstrated that patients with diabetes mellitus are more prone to suffer from LI, and diabetes mellitus and being older than 65 are independent risk factors (28) for LI. Type-2 diabetes mellitus is correlated with a higher risk of lacunar stroke (29), while prediabetes mellitus and persistent $\mathrm{HbA1C}$ are significantly correlated with an increased risk of LI or WMH (11). After an adjustment for multiple factors, type-2 diabetes mellitus 
Table 2 Potential risk factors related to Lacunar infarction in the DM group and IGT group

\begin{tabular}{|c|c|c|c|}
\hline Category & $\begin{array}{l}\text { Patients with lacunar infarction in } \\
\text { DM group and IGT group }\end{array}$ & $\begin{array}{l}\text { Patients without lacunar infarction in } \\
\text { DM group and IGT group }\end{array}$ & $\mathrm{P}$ \\
\hline Male & $189(63.0)$ & $60(78.9)$ & $0.009^{*}$ \\
\hline $\mathrm{BMI}\left(\mathrm{kg} / \mathrm{m}^{2}\right)$ & $25(23.2-27.175)$ & $27.1(24.975-28.850)$ & $<0.001^{\star}$ \\
\hline $\mathrm{TC}(\mathrm{mmol} / \mathrm{L})$ & $4.32(3.6-4.92)$ & $4.4(3.83-5.06)$ & 0.295 \\
\hline $\mathrm{SCr}(\mu \mathrm{mol} / \mathrm{L})$ & $78.4(67.2-89.5)$ & $78.5(69.5-86.9)$ & 0.895 \\
\hline Hypertension history & $227(75.7)$ & $52(68.4)$ & 0.197 \\
\hline $\mathrm{BP}$ & & & 0.251 \\
\hline Normal & $73(24.3)$ & $24(31.6)$ & \\
\hline Grade 3 (>180 mmHg) & $124(41.3)$ & $24(31.6)$ & \\
\hline BP satisfied controlled proportion & $128(42.7)$ & $39(51.3)$ & 0.175 \\
\hline Using antihypertensive drugs & $194(64.7)$ & $38(50.0)$ & $0.019^{*}$ \\
\hline Using statins & $121(40.3)$ & $15(19.7)$ & $0.001^{*}$ \\
\hline Using aspirin & $124(41.3)$ & $13(17.1)$ & $<0.001^{\star}$ \\
\hline CHD history & $57(19.0)$ & $6(7.9)$ & $0.021^{*}$ \\
\hline Smoking & $130(43.3)$ & $40(52.6)$ & 0.146 \\
\hline Smoking years & & & 0.090 \\
\hline$<5$ years & $48(16.0)$ & $29(38.2)$ & \\
\hline$>5$ and $\leq 9$ years & $52(17.3)$ & $8(10.5)$ & \\
\hline$>10$ and $\leq 19$ years & $75(25)$ & $7(9.2)$ & \\
\hline$\geq 20$ years & $50(16.7)$ & $1(1.3)$ & \\
\hline \multicolumn{4}{|l|}{$\mathrm{HbA}_{1} \mathrm{C}$ management } \\
\hline$<6$ & 99 (33.0) & $35(46.1)$ & $0.034^{\star}$ \\
\hline$\geq 6$ & $201(67.0)$ & 41 (53.9) & \\
\hline Using insulin & & & $<0.001^{\star}$ \\
\hline No & $211(70.3)$ & $70(92.1)$ & \\
\hline Yes & $89(29.7)$ & $6(7.9)$ & \\
\hline
\end{tabular}

Data are expressed as $\mathrm{n}(\%)$ and median (interquartile range). ${ }^{*}, \mathrm{P}<0.05$, the difference is statistically significant. IGT, impaired glucose tolerance; DM, diabetes mellitus; BMI, body mass index; TC, total cholesterol; TG, triglyceride; SCr, serum creatinine; WMH, white matter hyperintensities; FBG, fasting blood glucose; CHD, coronary heart disease; HBP, high blood pressure; HbA1C, Glycated hemoglobin test; $\mathrm{BP}$, blood pressure. 
Table 3 Potential risk factors related to WMHs in the DM group and IGT group

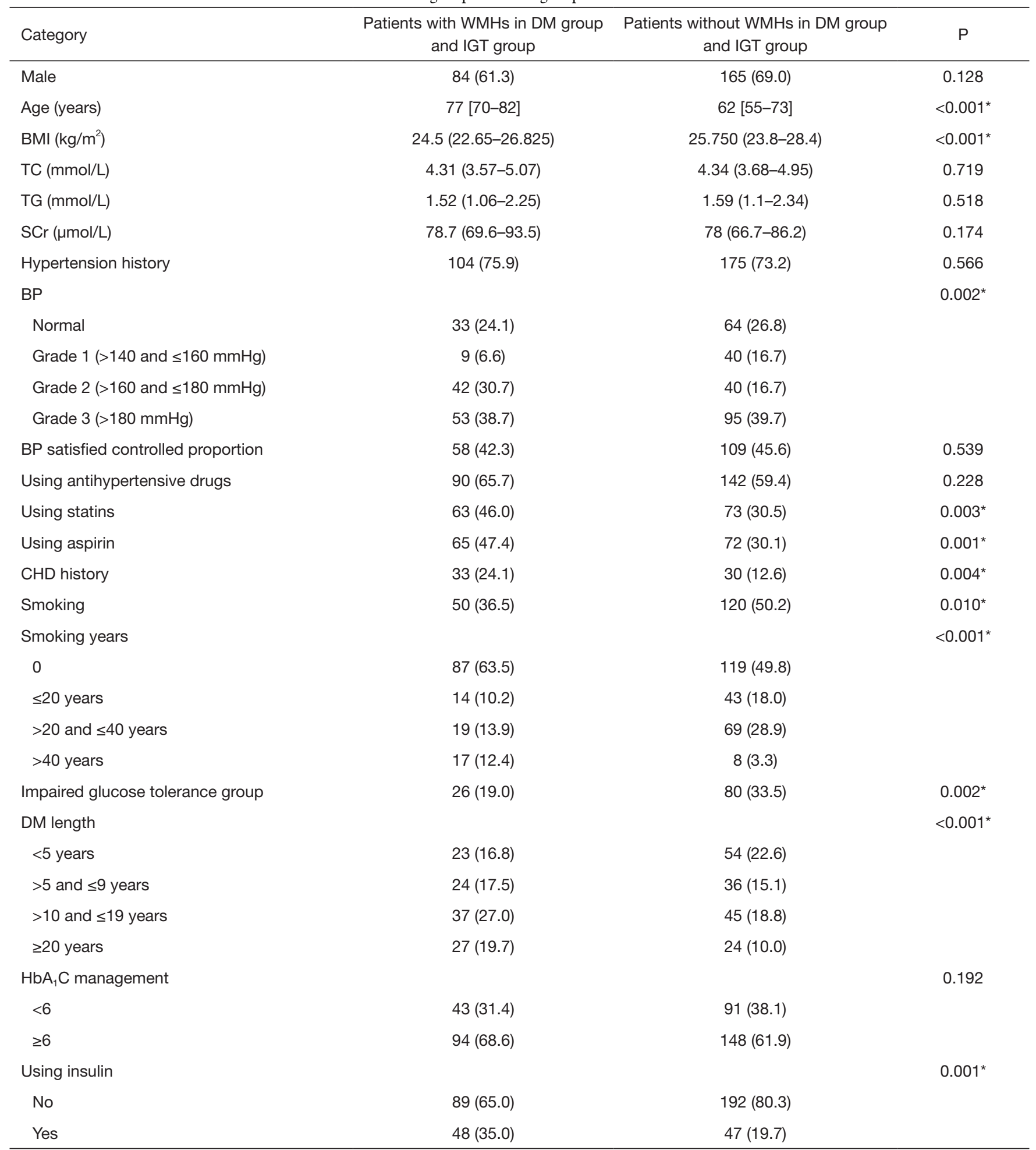

Data are expressed as $\mathrm{n}(\%)$ and median (interquartile range). ${ }^{*}, \mathrm{P}<0.05$, the difference is statistically significant. IGT, impaired glucose tolerance; DM, diabetes mellitus; BMI, body mass index; TC, total cholesterol; TG, triglyceride; SCr, serum creatinine; WMH, white matter hyperintensities; FBG, fasting blood glucose; CHD, coronary heart disease; HBP, high blood pressure; HbA1C, Glycated hemoglobin test; BP, blood pressure. 
Table 4 The relationship between the diabetes-related factors and brain changes (lacunes, WMHs) in patients in the DM group

\begin{tabular}{|c|c|c|c|c|c|}
\hline Brain changes & Variables & Regression coefficient & OR value (odds ratio) & $95 \%$ confidence interval $(95 \% \mathrm{Cl})$ & $\mathrm{P}$ \\
\hline \multirow{3}{*}{ Lacunar infarction } & $\mathrm{HbA1C}$ management & 0.069 & 1.071 & $0.556-2.063$ & 0.953 \\
\hline & Insulin use & 0.881 & 2.413 & $0.801-7.27$ & 0.133 \\
\hline & Age & 0.132 & 1.141 & $1.102-1.18$ & $<0.001^{*}$ \\
\hline \multirow{3}{*}{ WMH } & $\mathrm{HbA} 1 \mathrm{C}$ management & -0.242 & 0.785 & $0.449-1.374$ & 0.421 \\
\hline & Insulin use & 0.613 & 1.846 & $0.937-3.638$ & 0.078 \\
\hline & Age & 0.117 & 1.124 & $1.094-1.155$ & $<0.001^{\star}$ \\
\hline
\end{tabular}

*, $\mathrm{P}<0.05$, the difference is statistically significant. $\mathrm{WMH}$, white matter hyperintensities; $\mathrm{DM}$, diabetes mellitus.

may be one of the key determinants of microangiopathy, which is dominated by white-matter lesions (30). When based on a longitudinal comparison, diabetes mellitus is correlated with larger white-matter high-intensity volume, and from a horizontal comparison perspective, diabetes mellitus is correlated with accelerated white-matter highintensity accumulation (13); the volume of WMHs and the number of WMH lesions are significantly correlated with diabetes mellitus (31). Prediabetes mellitus and type2 diabetes mellitus are associated with fewer white-matter connections and weaker white-matter network tissue (32), while insulin-like growth factor binding protein-3 is negatively correlated with the severity of WMHs in patients with type- 2 diabetes mellitus compared with the control group $(\mathrm{P}<0.05)(33)$. However, some findings are not consistent, with no difference in periventricular WMHs between patients with and without diabetes mellitus. In contrast, deep WMHs have been found only in the control group (23). No correlations between prediabetes mellitus and lacunes, CMBs, WMHs, or smaller brain volumes have been observed in the older population (24), and most studies have demonstrated that lacunes or WMHs are more common in patients with type-2 diabetes mellitus. It is currently believed that insulin resistance in the bloodbrain barrier reduces the amount of glucose reaching the brain, leading to neuronal damage. The diabetic state may lead to a hyperglycemic state in the brain, which leads to the formation of advanced glycation end products, further triggering the neuroinflammation $(34,35)$; this may also be correlated with reduced cerebral blood flow, increased middle cerebral artery resistance, and inflammation (36,37). Chronic hyperglycemia changes cell-membrane permeability reduces local blood flow, and results in permanent cell damage. In the present study, people with type-2 diabetes mellitus, impaired glucose tolerance, and a control group were studied in relation to four MRI markers of CSVD: lacunes, WMHs, CMBs, and perivascular space. The results demonstrated that compared with the control group and impaired glucose tolerance group, the prevalence of lacunes and WMHs in the type-2 diabetes mellitus group was higher. However, there was no significant difference in the incidence of CMBs and perivascular space. There are also some studies suggesting that gender could lead to different stroke risks caused by cerebrovascular diseases between men and women, and women with diabetes have a worse prognosis $(38,39)$. These results are of great significance for us to further understand diabetes and the risk of cerebrovascular diseases. Unfortunately, this study did not conclude that there are gender differences in risk factors, which may have a certain relationship with the method of inclusion in this study.

Currently, there are few studies on the metabolic and vascular determinants of brain imaging abnormalities in patients with type-2 diabetes mellitus. The present study found that in patients with abnormal blood glucose, the occurrence of lacunes was correlated with the duration of diabetes mellitus, HbA1C, and insulin use, but it was only independently correlated with the duration of diabetes mellitus. HbA1C levels were not correlated with brain structural features. It was not possible to assess the correlation between actual hyperglycemia or normal glucose duration and the effects of persistent or transient hyperglycemia on brain structural characteristics in patients with diabetes mellitus, as HbA1C levels only provide estimates within average glucose levels. A study similar to this study showed that compared with subjects 
who had suffered from diabetes mellitus for less than 10 years, subjects who had been diabetic for 10 years or more had a greater number of lacunes $(\mathrm{P}<0.05)(24)$. However, another study showed that in a fully adjusted model, fasting glucose, HbA1C, and diabetes mellitus duration were not correlated with lacunes in subjects with type- 2 diabetes mellitus $(\mathrm{P}>0.05)$ (40). In the present study, the use of antihypertensive drugs, statins, and aspirin was found to be greater in LI patients than in the control group $(\mathrm{P}<0.05)$, which may be related to the fact that all patients in our study were inpatients. Inpatients had increased opportunities to take these drugs when CSVD was diagnosed and confirmed.

In the present study, it was also found that in patients with abnormal blood glucose, the occurrence of WMHs was correlated to the duration of diabetes mellitus and use of insulin. Moreover, it was observed that the incidence of grade 2 hypertension was higher in the patients with WMHs $(\mathrm{P}<0.05)$. Some previous studies have shown that the duration of diabetes mellitus was correlated with the volume of WMHs $(24,41)$ and that higher systolic pressure (beats per minute) was correlated with WMH progression $(42,43)$. However, after multiple adjustments, the present study found that the occurrence of WMHs was only independently correlated with age. Some studies on WMHs using diffusion tensor imaging (DTI) technology have demonstrated (44) that diabetic patients presented with a loss of microstructures, which was reflected in a reduction in FA, rather than correlating with age (45). A study of healthy young adults showed that even in young adults, high blood glucose resulted in reduced white-matter integrity (46), and two studies on adolescents with type- 2 diabetes mellitus and white-matter lesions also found a decrease in FA in the type-2 diabetes mellitus group $(47,48)$. These results are not consistent with those of the present study. The next step in this study is to use MRI and DTI sequencing to further investigate the clinical determinants of WMHs in diabetic patients.

One advantage of this study is that it focuses on relatively older DM patients, who are more than 55 years old. Another advantage is that it focuses not only on diabetic patients, but also patients with impaired glucose tolerance. This study has some limitations. Firstly, this study is a retrospective study, limited by previous scan results, this study is unable to provide GRE and SWI scan results, and thus cannot study the perivascular space, cerebral microhemorrhage, and brain atrophy. Secondly, when the patients in the Control group were included, they were only concerned about whether the diagnosis of diabetes and impaired glucose tolerance was definitive, so only those who met the inclusion criteria, the oral glucose tolerance test was completed, the results of fasting blood glucose and glycosylated hemoglobin were obtained, were included. After the inclusion, the included patients were not further matched, resulting in poor comparability in the Control group and the possibility of selection bias. Thirdly, the possibility of unobserved confounding factors will affect the results of the study, and the cross-sectional study setting also limits the causal explanation. Fourthly, the statistical method used in this study is controversial. This study did not include all potential variables into the regression analysis, but only studied the correlation relationship between the four clinically concerned variables and the 2 types of CSVD in diabetes mellitus group, and the analysis about another variables were not sufficient.

The conclusions of the present study are that lacunes and WMHs are more common in type-2 diabetes mellitus than in the controls and patients with impaired glucose tolerance. The duration of diabetes mellitus and the age of patients are correlated with the occurrence of lacunes, but the occurrence of WMHs is independently correlated with age. More advanced multiparameter MRI technology will be used for future studies to investigate brain structural changes in patients with type-2 diabetes mellitus and their effects on cognitive function, as well as potential pathophysiological mechanism (49).

\section{Acknowledgments}

Funding: This work was supported by National Key Research and Development Program "Pathogenesis and New Clinical Diagnosis and Treatment strategy of Chronic cerebral small vessels" (No. 2016YFC1300600).

\section{Footnote}

Reporting Checklist: The authors have completed the STROBE reporting checklist. Available at https://qims. amegroups.com/article/view/10.21037/qims-21-786/rc

Conflicts of Interest: All authors have completed the ICMJE uniform disclosure form (available at https://qims. amegroups.com/article/view/10.21037/qims-21-786/coif). The authors have no conflicts of interest to declare.

Ethical Statement: The authors are accountable for all aspects of the work in ensuring that questions related 
to the accuracy or integrity of any part of the work are appropriately investigated and resolved. The study was conducted in accordance with the Declaration of Helsinki (as revised in 2013). The study was approved by Ethics Committee of Shanxi Bethune Hospital (SBQLL-2021-066) and informed consent was taken from all the patients.

Open Access Statement: This is an Open Access article distributed in accordance with the Creative Commons Attribution-NonCommercial-NoDerivs 4.0 International License (CC BY-NC-ND 4.0), which permits the noncommercial replication and distribution of the article with the strict proviso that no changes or edits are made and the original work is properly cited (including links to both the formal publication through the relevant DOI and the license). See: https://creativecommons.org/licenses/by-nc-nd/4.0/.

\section{References}

1. Ma RCW. Epidemiology of diabetes and diabetic complications in China. Diabetologia 2018;61:1249-60.

2. Weng J, Ji L, Jia W, Lu J, Zhou Z, Zou D, et al. Standards of care for type 2 diabetes in China. Diabetes Metab Res Rev 2016;32:442-58.

3. Wang L, Gao P, Zhang M, Huang Z, Zhang D, Deng Q, Li Y, Zhao Z, Qin X, Jin D, Zhou M, Tang X, Hu Y, Wang L. Prevalence and Ethnic Pattern of Diabetes and Prediabetes in China in 2013. JAMA 2017;317:2515-23.

4. Jia W, Weng J, Zhu D, Ji L, Lu J, Zhou Z, et al. Standards of medical care for type 2 diabetes in China 2019. Diabetes Metab Res Rev 2019;35:e3158.

5. Pantoni L. Cerebral small vessel disease: from pathogenesis and clinical characteristics to therapeutic challenges. Lancet Neurol 2010;9:689-701.

6. Wardlaw JM, Smith EE, Biessels GJ, Cordonnier C, Fazekas F, Frayne R, et al. Neuroimaging standards for research into small vessel disease and its contribution to ageing and neurodegeneration. Lancet Neurol 2013;12:822-38.

7. Grau-Olivares M, Arboix A, Bartrés-Faz D, Junqué C. Neuropsychological abnormalities associated with lacunar infarction. J Neurol Sci 2007;257:160-5.

8. Groeneveld O, Reijmer Y, Heinen R, Kuijf H, Koekkoek P, Janssen J, Rutten G, Kappelle L, Biessels G; COGID study group. Brain imaging correlates of mild cognitive impairment and early dementia in patients with type 2 diabetes mellitus. Nutr Metab Cardiovasc Dis 2018;28:1253-60.
9. Imano H, Iso H, Kitamura A, Yamagishi K, HayamaTerada M, Muraki I, Okada T, Umesawa M, Ohira T, Sankai T, Cui R, Tanigawa T, Kiyama M; CIRCS Investigators. Nonfasting Glucose and Incident Stroke and Its Types - The Circulatory Risk in Communities Study (CIRCS). Circ J 2018;82:1598-604.

10. Hirabayashi N, Hata J, Ohara T, Mukai N, Nagata M, Shibata M, Gotoh S, Furuta Y, Yamashita F, Yoshihara K, Kitazono T, Sudo N, Kiyohara Y, Ninomiya T. Association Between Diabetes and Hippocampal Atrophy in Elderly Japanese: The Hisayama Study. Diabetes Care 2016;39:1543-9.

11. Zhou JB, Tang XY, Han YP, Luo FQ, Cardoso MA, Qi L. Prediabetes and structural brain abnormalities: Evidence from observational studies. Diabetes Metab Res Rev 2020;36:e3261.

12. Exalto LG, van der Flier WM, Scheltens P, Vrenken H, Biessels GJ. Dysglycemia, brain volume and vascular lesions on MRI in a memory clinic population. J Diabetes Complications 2014;28:85-90.

13. Marseglia A, Fratiglioni L, Kalpouzos G, Wang R, Bäckman L, Xu W. Prediabetes and diabetes accelerate cognitive decline and predict microvascular lesions: A population-based cohort study. Alzheimers Dement 2019;15:25-33.

14. de Bresser J, Kuijf HJ, Zaanen K, Viergever MA, Hendrikse J, Biessels GJ; Utrecht Vascular Cognitive Impairment Study Group. White matter hyperintensity shape and location feature analysis on brain MRI; proof of principle study in patients with diabetes. Sci Rep 2018;8:1893.

15. van Agtmaal MJM, Houben AJHM, de Wit V, Henry RMA, Schaper NC, Dagnelie PC, van der Kallen CJ, Koster A, Sep SJ, Kroon AA, Jansen JFA, Hofman PA, Backes WH, Schram MT, Stehouwer CDA. Prediabetes Is Associated With Structural Brain Abnormalities: The Maastricht Study. Diabetes Care 2018;41:2535-43.

16. Rist PM, Buring JE, Rexrode KM, Cook NR, Rost NS. Prospectively collected lifestyle and health information as risk factors for white matter hyperintensity volume in stroke patients. Eur J Epidemiol 2019;34:957-65.

17. Sanahuja J, Alonso N, Diez J, Ortega E, Rubinat E, Traveset A, Alcubierre N, Betriu À, Castelblanco E, Hernández M, Purroy F, Arcidiacono MV, Jurjo C, Fernández E, Puig-Domingo M, Groop PH, Mauricio D. Increased Burden of Cerebral Small Vessel Disease in Patients With Type 2 Diabetes and Retinopathy. Diabetes Care 2016;39:1614-20. 
18. Zhou H, Yang J, Xie P, Dong Y, You Y, Liu J. Cerebral microbleeds, cognitive impairment, and MRI in patients with diabetes mellitus. Clin Chim Acta 2017;470:14-9.

19. Umemura T, Kawamura T, Hotta N. Pathogenesis and neuroimaging of cerebral large and small vessel disease in type 2 diabetes: A possible link between cerebral and retinal microvascular abnormalities. J Diabetes Investig 2017;8:134-48.

20. Blevins BL, Vinters HV, Love S, Wilcock DM, Grinberg LT, Schneider JA, et al. Brain arteriolosclerosis. Acta Neuropathol 2021;141:1-24.

21. Caunca MR, Del Brutto V, Gardener H, Shah N, Dequatre-Ponchelle N, Cheung YK, Elkind MS, Brown TR, Cordonnier C, Sacco RL, Wright CB. Cerebral Microbleeds, Vascular Risk Factors, and Magnetic Resonance Imaging Markers: The Northern Manhattan Study. J Am Heart Assoc 2016;5:003477.

22. Qiu C, Cotch MF, Sigurdsson S, Garcia M, Klein R, Jonasson F, Klein BE, Eiriksdottir G, Harris TB, van Buchem MA, Gudnason V, Launer LJ. Retinal and cerebral microvascular signs and diabetes: the age, gene/ environment susceptibility-Reykjavik study. Diabetes 2008;57:1645-50.

23. Sundar U, Manwatkar AA, Joshi AR, Bhandarkar P. The Effect of Hypertension and Diabetes Mellitus on White Matter Changes in MRI Brain: A Comparative Study between Patients with Alzheimer's Disease and an Age-matched Control Group. J Assoc Physicians India 2019;67:14-7.

24. Schneider ALC, Selvin E, Sharrett AR, Griswold M, Coresh J, Jack CR Jr, Knopman D, Mosley T, Gottesman RF. Diabetes, Prediabetes, and Brain Volumes and Subclinical Cerebrovascular Disease on MRI: The Atherosclerosis Risk in Communities Neurocognitive Study (ARIC-NCS). Diabetes Care 2017;40:1514-21.

25. Alberti KG, Zimmet PZ. Definition, diagnosis and classification of diabetes mellitus and its complications. Part 1: diagnosis and classification of diabetes mellitus provisional report of a WHO consultation. Diabet Med 1998;15:539-53.

26. Whelton PK, Carey RM, Aronow WS, Casey DE Jr, Collins KJ, Dennison Himmelfarb C, et al. 2017 ACC/ AHA/AAPA/ABC/ACPM/AGS/APhA/ASH/ASPC/ NMA/PCNA Guideline for the Prevention, Detection, Evaluation, and Management of High Blood Pressure in Adults: A Report of the American College of Cardiology/ American Heart Association Task Force on Clinical Practice Guidelines. J Am Coll Cardiol 2018;71:e127-248.
27. Kim KW, MacFall JR, Payne ME. Classification of white matter lesions on magnetic resonance imaging in elderly persons. Biol Psychiatry 2008;64:273-80.

28. Wei LM, Zhu YQ, Bao YQ, Lu HT, Zhang PL, Zhao YW, Li M, Zhao JG. Atherosclerosis in intracranial or extracranial vessels in diabetic patients and the association with stroke subtype. Quant Imaging Med Surg 2019;9:960-7.

29. Liu J, Rutten-Jacobs L, Liu M, Markus HS, Traylor M. Causal Impact of Type 2 Diabetes Mellitus on Cerebral Small Vessel Disease: A Mendelian Randomization Analysis. Stroke 2018;49:1325-31.

30. ParkJH, Ryoo S, Kim SJ, Kim GM, Chung CS, Lee $\mathrm{KH}$, Bang OY. Differential risk factors for lacunar stroke depending on the MRI (white and red) subtypes of microangiopathy. PLoS One 2012;7:e44865.

31. Lucatelli P, Montisci R, Sanfilippo R, Sacconi B, Suri JS, Catalano C, Saba L. Is there an association between leukoaraiosis volume and diabetes? J Neuroradiol 2016;43:273-9.

32. Vergoossen LW, Schram MT, de Jong JJ, Stehouwer CD, Schaper NC, Henry RM, van der Kallen CJ, Dagnelie PC, van Boxtel MP, Eussen SJ, Backes WH, Jansen JF. White Matter Connectivity Abnormalities in Prediabetes and Type 2 Diabetes: The Maastricht Study. Diabetes Care 2020;43:201-8.

33. Hjortebjerg R, Laugesen E, Høyem P, Oxvig C, StausbølGrøn B, Knudsen ST, Kim WY, Poulsen PL, Hansen TK, Bjerre M, Frystyk J. The IGF system in patients with type 2 diabetes: associations with markers of cardiovascular target organ damage. Eur J Endocrinol 2017;176:521-31.

34. Wang M, Norman JE, Srinivasan VJ, Rutledge JC. Metabolic, inflammatory, and microvascular determinants of white matter disease and cognitive decline. Am J Neurodegener Dis 2016;5:171-7.

35. Convit A. Links between cognitive impairment in insulin resistance: an explanatory model. Neurobiol Aging 2005;26 Suppl 1:31-5.

36. Novak V, Last D, Alsop DC, Abduljalil AM, Hu K, Lepicovsky L, Cavallerano J, Lipsitz LA. Cerebral blood flow velocity and periventricular white matter hyperintensities in type 2 diabetes. Diabetes Care 2006;29:1529-34.

37. Shen Y, Zhao B, Yan L, Jann K, Wang G, Wang J, Wang B, Pfeuffer J, Qian T, Wang DJJ. Cerebral Hemodynamic and White Matter Changes of Type 2 Diabetes Revealed by Multi-TI Arterial Spin Labeling and Double Inversion Recovery Sequence. Front Neurol 2017;8:717. 
38. Arboix A, Cartanyà A, Lowak M, García-Eroles L, Parra O, Oliveres M, Massons J. Gender differences and womanspecific trends in acute stroke: results from a hospitalbased registry (1986-2009). Clin Neurol Neurosurg 2014;127:19-24.

39. Arboix A, Milian M, Oliveres M, García-Eroles L, Massons J. Impact of female gender on prognosis in type 2 diabetic patients with ischemic stroke. Eur Neurol 2006;56:6-12.

40. Raffield LM, Cox AJ, Freedman BI, Hugenschmidt CE, Hsu FC, Wagner BC, Xu J, Maldjian JA, Bowden DW. Analysis of the relationships between type 2 diabetes status, glycemic control, and neuroimaging measures in the Diabetes Heart Study Mind. Acta Diabetol 2016;53:439-47.

41. de Bresser J, Tiehuis AM, van den Berg E, Reijmer YD, Jongen C, Kappelle LJ, Mali WP, Viergever MA, Biessels GJ; Utrecht Diabetic Encephalopathy Study Group. Progression of cerebral atrophy and white matter hyperintensities in patients with type 2 diabetes. Diabetes Care 2010;33:1309-14.

42. Hawkins KA, Emadi N, Pearlson GD, Winkler AM, Taylor B, Dulipsingh L, King D, Pittman B, Blank K. Hyperinsulinemia and elevated systolic blood pressure independently predict white matter hyperintensities with associated cognitive decrement in the middleaged offspring of dementia patients. Metab Brain Dis 2017;32:849-57.

43. de Havenon A, Majersik JJ, Tirschwell DL, McNally JS, Stoddard G, Rost NS. Blood pressure, glycemic control,

Cite this article as: Wang DQ, Wang L, Xia XS, Wei MM, Tian XL, Wang LF, Li X. Clinical and MRI features about two types of silent cerebral small-vessel disease in type-2 diabetes mellitus: a retrospective cross-sectional study in a tertiary hospital. Quant Imaging Med Surg 2022;12(4):2385-2396. doi: 10.21037/qims-21-786 and white matter hyperintensity progression in type 2 diabetics. Neurology 2019;92:e1168-75.

44. Wang DQ, Wang L, Wei MM, Xia XS, Tian XL, Cui XH, Li X. Relationship Between Type 2 Diabetes and White Matter Hyperintensity: A Systematic Review. Front Endocrinol (Lausanne) 2020;11:595962.

45. de Groot M, Ikram MA, Akoudad S, Krestin GP, Hofman A, van der Lugt A, Niessen WJ, Vernooij MW. Tractspecific white matter degeneration in aging: the Rotterdam Study. Alzheimers Dement 2015;11:321-30.

46. Weinstein G, Maillard P, Himali JJ, Beiser AS, Au R, Wolf PA, Seshadri S, DeCarli C. Glucose indices are associated with cognitive and structural brain measures in young adults. Neurology 2015;84:2329-37.

47. Nouwen A, Chambers A, Chechlacz M, Higgs S, Blissett J, Barrett TG, Allen HA. Microstructural abnormalities in white and gray matter in obese adolescents with and without type 2 diabetes. Neuroimage Clin 2017;16:43-51.

48. Rofey DL, Arslanian SA, El Nokali NE, Verstynen T, Watt JC, Black JJ, Sax R, Krall JS, Proulx C, Dillon M, Erickson KI. Brain volume and white matter in youth with type 2 diabetes compared to obese and normal weight, non-diabetic peers: A pilot study. Int J Dev Neurosci 2015;46:88-91.

49. Deng L, Liu H, Liu H, Liu J, Liu W, Liu Y, Zhang Y, Rong P, Liang Q, Wang W. Concomitant functional impairment and reorganization in the linkage between the cerebellum and default mode network in patients with type 2 diabetes mellitus. Quant Imaging Med Surg 2021;11:4310-20. 